\title{
Student-Athletes' Perceptions of Coaches' Coaching Competency at the Malaysian Public Institution of Higher Learning
}

\author{
Lim Khong Chiu ${ }^{1, *}$, Nor Idayu Mahat ${ }^{2}$, Khor Phoy Hua ${ }^{3} \&$ Radzliyana Bt Radzuwan ${ }^{3}$ \\ ${ }^{1}$ School of Tourism, Hospitality and Environmental Management, Universiti Utara Malaysia, Malaysia \\ ${ }^{2}$ School of Quantitative Sciences, Universiti Utara Malaysia, Malaysia \\ ${ }^{3}$ Sport Science and Recreation Unit, Universiti Institut Teknologi MARA, Perlis, Malaysia \\ *Corresponding author: School of Tourism, Hospitality and Environmental Management, Universiti Utara Malaysia, \\ Malaysia Tel: 60-19-458-6478 E-mail: lkc@uum.edu.my
}

Received: November 30, $2012 \quad$ Accepted: December 24, 2012 Online Published: January 9, 2013

doi:10.5430/wje.v3n1p13 URL: http://dx.doi.org/10.5430/wje.v3n1p13

The research is financed by Universiti Utara Malaysia and Research Innovation Management Centre.

\begin{abstract}
This study was designed to evaluate the competency level of coaches at the higher institutions' sports competitions organized by the Universities Sports Council of Malaysia. Multi-dimensional model of leadership behaviors and models of coaching effectiveness were used as the basis for the theoretical framework. A total of 322 student-athletes comprising $183(57.2 \%)$ men and $137(44.8 \%)$ women were participated in the questionnaire survey. Researchers have adapted the Coaching Competency Scale for data collection. The results of this study indicate that the coaches' competency level were not differ significantly by gender and performance of student-athletes, but it was differed significantly by type of sport, between team and individual sports. The information from this study may help coaches to some extent in planning strategies for coaching athletes to ensure the effectiveness of its role as a coach.
\end{abstract}

Keywords: coaching competency; coaching competency scale; sport coach; student-athlete; public university

\section{Introduction}

Coaching is a complex task and required the use of different strategies and behaviors to fulfill many expectations. Sports coaches have to possess good knowledge, skills and high motivation in carrying out responsibilities to produce quality athletes. It has been proven that behavior of a coach may determine his competency in designing effective training hence influence excellent achievement among his athletes (Kuga, 1993, Myers, Feltz, Maier, Wolfe \& Reckase, 2006). As a matter of fact, a competent coach that gives high satisfaction to his athletes may motivate them to perform confidently in their games. Thus, the type of leadership behavior portrayed by the coach can have a significant effect on performance and psychological well-being of athlete (Horn, 2002). The context of the sport situation and the characteristics of the coach and the athletes themselves prescribe appropriate leadership behavior. Consequently, effective coaching behavior varies across specific contexts as the characteristics of the athletes and the prescribed situation change (Chelladurai, 1990). Hersey and Blanchard (1977) discovered that coaches' leadership may change to assimilate with environments. These environments are often explained by total of given order (task behavior), emotional support (relationship behavior) and level of maturity. Therefore, a competent coach should possess some skills in choosing the right approach, technique and tune of language when approaching their athletes.

The term, "competency", refers to the knowledge, skills and performance abilities required to perform a job effectively. Some may also refer to these as motives, traits, skills and abilities (Dalton, 1997). Thus, the concerns on coaching competency among sports coaches are common in high achievable sports country such as Germany, United States and Australia. In Asia countries, China, Japan and South Korea are good exemplary due to accelerate performance in world class tournaments. Interestingly, these countries have minimum dependencies on foreigners' experts in producing world class athletes. Malaysia possesses some world class athletes especially in badminton, diving, squash and cycling but they face some difficulties to maintain such reputable position due to (i) lack of 
replacement athletes, (ii) incompetence coaches and (iii) internal issues arose in the sports body. Some local studies have reported that the quality of coaching or training in Malaysia is less encouraging (Rahim Harun, 1992; Khoo Kay Kim, 1991, 1994, 1995). Former coach for hockey national team, Terry Walsh (1988), claimed that Malaysia is left behind in promoting scientific knowledge in sports thus unable to provide new techniques in coaching systems. A serious commented by Han Peter Thumm in local news, Berita Harian on 28 December 1990, that local coaches are incompetence to train sportsmen at states and country level. The notion was further supported by Sieh Kok Chi, the Olympic Council of Malaysia secretary, by stressing that the shortcomings of Malaysian sports was partly due to incompetent coaches, and thus, Malaysia should start with training the respective coaches first to bring back the sports culture in Malaysia (The Star, September 19, 2004).

To react with such comments, students' involvement in sports has been given serious attention in Malaysia where this commitment is counted in getting a place in local higher education institution. In fact, annual sports tournaments among higher education institutions are organized to support in supplying talented athletes for the country. In connection to this, every higher education institution has a pool of sports coaches to prepare institution's team for the tournaments. However, the issue here is, whether universities' coaches possess good competency in bringing up potential athletes for the country?

While the coach is constantly making evaluations about his/her athletes, student-athletes are also formulating assessments about their coach's personality and behavior. These perceptions of coaching competency could alter the performance of the student-athletes and could offer important insights into valuable information needed to improve this relationship (Cratty, 1989). In addition, it seems appropriate to consider the perspectives of student-athletes when evaluating coaching performance. Particularly important is the notion of conducting a broad comprehensive evaluation which will elicit an accurate profile of an individual's performance (Adams, 1979). However, a little research has been given emphasis on coaches' coaching competency in the Public Institution of Higher Learning (IPTA). Thus, the purpose of this study is to evaluate the coaching competency of coaches at 2010 IPTA sport competition from the perspective of the student-athletes.

\subsection{Research Questions}

The specific research questions addressed in this study included the following:

a) What are student-athletes perceptions of coach's coaching competency based on their gender differences, sport categories (individual/team), and performance (win/loss) at 2010 IPTA sport competition?

b) Are there different levels of competency in accordance with the perceptions of student-athletes?

c) Does the performance of student-athletes is influenced by length of experience under supervision of their coaches?

\section{Review of Literature}

The role of coaching in sports is important to ensure quality athletes in competition. Philips (2007) and Paling (2004) concluded that coaches play various roles in their profession. For example, coaches are asked to be teachers, organizers, motivators, leaders, and counselor. Williams, Jerome, Kenow, Rogers and Sartain (2003) stressed that coaches ensure quality and the effectiveness of any sports program. However, the most important successful factor of a coach is to help athletes to improve their athletic skill in a wide range of tasks from sequential development and mastery of basic skills for beginners, to the more specialized physical, technical, tactical, and psychological preparation of elite athletes (Bompa, 1999; Martens, 1987). These functions are normally accomplished by the coach engaging in leadership behavior that effectively elicits appropriate actions from the athletes towards achieving set goals, in competitive or practice situations.

Coaching competencies are a source of competitive advantage in any sports. It is a complex task that needs specific strategies and behavior to fulfill certain expectations. Coaching competencies consist of various variables. Previous literatures have identified the relationship between coaching efficacy and coaching perceptions (Manning, 2007). Coaching efficacy can be regarded as the extent of beliefs among coaches on how it will affect learning and performance of athletes. Coaches need to have the ability and confident in aligning game strategies and athlete's strength with the aim of coordinating the team's strategy with the opponent's strengths and weaknesses. Four dimensions have been elaborated by Fung (2002) regarding coaching efficacy. They are motivation, strategy, technique and personality building.

As far as coaching competency is concerned, Myers et al. (2006) stated that there were three competency domains that were in the National Standards for Athletic Coaches (National Association for Sport and Physical Education, 
1995) but were left out of the Coaching Behaviour Questionnaire. These competencies were listed as (a) growth, development and learning of athlete, (b) psychological aspects of coaching, and (c) skills, tactics, and strategies. Thus, Myers et al. (2006) designed The Coaching Competency Scale (CCS) based upon these competencies. The specific competencies measured by the CCS included: character building competency (CBC), game strategy competency (GSC), motivation competency (MC), and technique competency (TC). The CCS had been validated and tested for reliability in their research on athletes' evaluation of their head coach's coaching competency and found to be psychometrically sound.

In addition, according to Myer et al. (2006), many instruments are designed to measure a coach's behavior. However, three instruments that are most prominent are the Coaching Behavior Assessment System (Smith, Smoll, \& Hunt, 1977), the Leadership Scale for Sports (Chelladurai \& Saleh, 1978, 1980), and a Decision Style Questionnaire (Chelladurai \& Arnot, 1985). Indeed, these instruments have also been used to assess athletes' perceptions of their coach's behavior (Horn, 2002). However, according to Myer et al. (2006), none measure athletes' evaluations of their coach's behavior.

In relation to coaches' leadership behavior, Chelladurai and Saleh (1978) reported that team sport athletes preference for training and instruction leadership style was significantly greater than that of individual sport athletes. Closed-sport (low-variability tasks) athletes also preferred significantly more training and instruction than did the open-sport athletes (high variability tasks). Terry and Howe (1984) found that athletes in independence sports (team sports) preferred more democratic and less autocratic behavior than did the athletes in interdependent sports. In another study by Terry (1984) reported that team sport athletes preferred significantly more training and instruction, autocratic behavior, and positive feedback, but less democratic behavior and social support than individual sport athletes. Besides, Schliesman (1987) has done a study on coaching leadership in individual sports. The purpose was to determine leadership behavior in sports and establishing the relationship between satisfaction and leadership among athletes. It was found that both democratic behavior and social support has a significant relationship. The higher the democratic behavior shown by coaches, the more social support the athletes will acquire. Even though the methodological aspect was questionable especially on sample selection, the finding has provided insights on coaches' behavior, these results lend support to path-goal theory (House, 1971), which postulates that when tasks are varied and interdependence, greater structure and closer supervision will be preferred.

In the context of gender, athlete gender has been tested across a wide-range of team and individual sports (Chelladurai \& Arnott, 1985; Chelladurai \& Saleh, 1978; Terry, 1984; Terry \& Howe, 1984; Lim 1995). However, in general, the degree of similarities or difference between genders in their coaching preferences is unclear and required further investigation. For instance, Terry and Howe (1984) investigated the coaching preferences of male and female varsity athletes. In examining the preferences of 160 athletes (male $=80$; female $=80$ ) from 16 sports, the researchers found considerable similarities between genders. Responses indicated that preference scores of the male athletes were significantly higher than those of the females athletes for autocratic only. Similarly, Terry (1984) investigated the coaching preferences of elite male and female intercollegiate athletes participating in a number of dual-gender sports, including basketball, volleyball, track \& field and swimming. The results indicated that male athletes prefer more autocratic behavior than female athletes do. This partially support Chelladurai and Saleh's (1978) findings that male athletes prefer more autocratic and social support behavior and female athletes prefer more democratic behavior.

The study in relation to coaching behaviour in the local Malaysia contexts, however, has been explored by Lim (1995) with the purpose to identify and determine the coaching behavior and their relationships with achievement motivation and satisfaction among athlete in secondary schools. By adapting the Leadership Scale for Sports (Chelladurai \& Saleh, 1978, 1980) for data collection, the results indicated that the training and instruction, and rewarding behavior are often exhibited by the coaches, and on the other hand autocratic behavior is seldom portrayed. In the perception of athletes, the findings indicated significant difference between men and women's perceptions on autocratic and social support behaviors. Male athletes seem to perceive their coaches portrayed more autocratic behavior and female athletes perceived their coaches exhibited more social support behavior. These findings are consistent with the previous studies such as by Chelladurai and Saleh, (1978), Terry (1984) and Terry and Howe (1984). Additionally, field games athletes (e.g. football, netball, softball) perceived their coaches portrayed more training and instruction behavior compared to court games athletes (e.g. volleyball, basketball).

However, a study by Abdul Hafidz and Norazman (2004) regarding the relationship between coaches' profile and athletes' performance shown that coaches' skills will not only help athletes in enhancing their physical, technical and psychological ability, but may educate athletes in their social and spiritual life. A qualitative approach (interview, 
document analysis and observation) was employed to compile data on coaches' profile, training program and athlete's achievement. The outcome of the study revealed that experience and qualification in coaching is imperative as determining factor towards athletes' performance either in individual or team sports. However, there were contradicting perceptions and views between coaches and managers that result in poor performance of the athletes. Coaching style should be tailored based on situational factor in order to secure success in sports. Coaches' individual philosophy, work ethics and professionalism with proper communication style will contribute significantly to the success in any sports and competition.

In conclusion, the coach-athlete-interaction, especially the leadership behavior of coaches, plays a crucial role in the development of young athletes' sport performance. Giving instructions and positive feedback seems to foster the development of sport skills. Thus, the type of leadership behavior displayed by the coach can have a significant effect on the performance and psychological well-being of the athlete (Horn, 1992).

\section{Method}

\subsection{Research Design}

This study was performed to get some empirical evidence about competency of coaches in higher education institutions in Malaysia. Specifically, it focused on student-athletes perceptions of the competency of their coaches at 2010 IPTA sports competition. A quantitative approach by using field survey method was used in this study. Four public universities in the northern peninsular of Malaysia have been chosen to collect data.

\subsection{Subjects}

A total of 322 student-athletes were chosen via purposive sampling technique as the subjects. They were identified by an athletic administrator at their respective universities. Student-athletes from various sports, including team and individual sports who were representing their respective universities in the IPTA sports competition were chosen to participate in this study.

\subsection{Instrumentation}

The instrument selected for the study was the Coaching Competency Scale (CCS) developed by Myers et al. (2006). The 24-item questionnaire in CCS was designed to measure four different dimensions. The four categories included motivation competency (MC), game strategy competency (GSC), techniques competency (TC), and character building competency (CBC). The definition of each dimension is given in Table 1.

Table 1: Definition of Four Dimensions of Coaches' Coaching Competency

\begin{tabular}{ll}
\hline \multicolumn{1}{c}{ Dimension of competency } & \multicolumn{1}{c}{ Definition } \\
\hline Motivation & Coaches' ability to affect mood psychology and skills of athletes. \\
Game strategy & $\begin{array}{l}\text { Coaches' ability to lead athletes during competition. } \\
\text { Techniques }\end{array}$ \\
Coaches' ability to make some diagnostics and giving instructions to \\
athletes. \\
Coaches' ability to influence athletes' personal development and positive \\
attitude towards sports.
\end{tabular}

Source: Myers et al. (2006)

All items of CCS are measured using a Likert scale of 10 points where (1) indicates "not at all competent" and (10) indicates "extremely competent". As suggested by Myers et al. (2006), this study will identify the level of competency on coaches based on the overall student-athletes perception score of the items. Competency is defined by Myers et al. (2006) as, "athletes' evaluations of their coach's ability to affect athletes' learning and performance" (p.452). The questionnaire was prepared in Malay (Malaysia national language) hence translation processes of CCS which originally in English were performed via back translation (Brislin, 1971). Then, we conducted a pilot test on the designed questionnaire to 290 respondents to evaluate reliability of the questionnaire. The results of this pilot test show that the measured reliability based on Cronbach's Alpha is a little bit higher than the ones reported by Myers et al. (2006) (see Table 2). Such findings allow us to use the translated questionnaire for actual study. 
Table 2: Internal Consistency of Coaches' Coaching Competency

\begin{tabular}{lcc}
\hline \multirow{2}{*}{ Dimension of competency } & \multicolumn{2}{c}{ Cronbach's Alpha Value } \\
\cline { 2 - 3 } & 0.9565 & Past literature \\
\hline Motivation & 0.9467 & Myers et el.(2006): \\
Games strategy & 0.9419 & Range from 0.82 to 0.92 for \\
Techniques & 0.9149 & each dimension of competency \\
Character building & 0.9844 & \\
Total coaching & & \\
\hline
\end{tabular}

\subsection{Procedures}

Permission to collect data with undergraduate students was received from selected university administrators. Questionnaires were administered by two trained research assistants as well as via the sport officer from respective universities to some chosen student-athletes who were participating and representing their university during the 2010 higher education institution sports competitions. Considering too many universities nationwide are costly hence we limited the sample to the four universities located in northern peninsular of Malaysia namely Perlis, Kedah and Penang. The subjects were asked to complete a survey questionnaire. Samples were informed concerning the purpose of the study and general instructions were provided, help was offered when needed, and responses were anonymous.

\subsection{Data Analysis}

The questionnaires collected were processed and analyzed with the SPSS/PC 16.0 statistical software package. The descriptive analyses were used to examine the means and standard deviations of each dimension of coaching competency according to gender, type of sports, and performance. T-test was performed to compare means differences between each group. Line graph was also plotted to present the relationship between the student-athletes' performance (win vs. loss) and the length of experience with their coach's supervision.

\section{Results and Discussion}

\subsection{Background of Sample}

The analysis on 322 samples of student-athletes showed that $57.20 \%$ were male and $42.80 \%$ were female. $60.25 \%$ of them involved in team sports, which comprises of at least two players in a team, and the remaining were in individual sports such as swimming, archery and golf. Since the study is conducted among student-athletes in universities, therefore $59.25 \%$ of our samples have their experience at most 12 months with their respective coaches. The obtained samples also indicate that $55 \%$ of them won the game that they had participating (winner, first runner up or second runner up) and $45 \%$ defeated.

\subsection{Coaches' Coaching Competency}

Research questions (a) and (b) asked "What are student-athletes perceptions of coach's coaching competency based on their gender differences, sport categories (individual/team), and performance (win/loss) at 2010 IPTA sports competition?" And "Are there different levels of competency in accordance with the perceptions of student-athletes?" Descriptive statistics were used to quantify each student-athletes' responses to the CCS. The mean values for each dimension according to each category are presented in Tables 3, 4, and 5. The investigation computed the average of total of competency and compared the groups of each factor statistically. The summarizations of the results are also tabulated in Tables 3, 4 and 5.

Competencies of coaches from gender point of views show that both male and female athletes rated their coaches with average total score close to the maximum score. This implies that the athletes find their coaches as possessing adequate level of knowledge, skills and experience in motivating, planning for strategy, imposing good techniques and building good characters for them. The results also show that the scores from both genders are not much difference. To confirm this, a statistical test was conducted on each dimension as displayed in the last column of Tables 3, 4, and 5. The result on each dimension shows that there is no significantly different of perceptions between genders hence gender is not a criterion that can distinguish level of competency among coaches. Based on these findings, we can also justify that coaches are not showing any signal of gender biased in training their athletes. They 
perhaps giving them exercises and coaching them suitable with their energy and physical.

Table 3: Student-athletes Perceptions on Coaching Competency in Terms of Gender

\begin{tabular}{|c|c|c|c|c|c|c|c|c|}
\hline \multirow{4}{*}{$\begin{array}{l}\text { Dimension of } \\
\text { Competency }\end{array}$} & \multirow{4}{*}{$\begin{array}{l}\text { Num. } \\
\text { of } \\
\text { items }\end{array}$} & \multirow{4}{*}{$\begin{array}{l}\text { Min. } \\
\text { score }\end{array}$} & \multirow{4}{*}{$\begin{array}{l}\text { Max. } \\
\text { score }\end{array}$} & \multicolumn{4}{|c|}{ Factors } & \multirow{4}{*}{$\begin{array}{l}\text { Test } \\
\text { differences } \\
\text { between } \\
\text { groups }\end{array}$} \\
\hline & & & & \multirow{2}{*}{\multicolumn{2}{|c|}{ Male }} & \multirow{2}{*}{\multicolumn{2}{|c|}{ Female }} & \\
\hline & & & & & & & & \\
\hline & & & & $M$ & $S D$ & $M$ & $S D$ & \\
\hline Motivation & 7 & 7 & 70 & 55.89 & 10.44 & 56.83 & 10.27 & $\begin{array}{l}t=-0.796 \\
(p=0.427)\end{array}$ \\
\hline Games strategy & 7 & 7 & 70 & 55.71 & 10.54 & 55.51 & 8.54 & $\begin{array}{l}t=0.182 \\
(p=0.856)\end{array}$ \\
\hline Techniques & 6 & 6 & 60 & 48.06 & 9.04 & 47.82 & 7.30 & $\begin{array}{l}t=0.247 \\
(p=0.805)\end{array}$ \\
\hline $\begin{array}{l}\text { Character } \\
\text { building }\end{array}$ & 4 & 4 & 40 & 31.93 & 6.12 & 32.47 & 4.62 & $\begin{array}{l}t=-0.847 \\
(p=0.397)\end{array}$ \\
\hline Total coaching & 24 & 24 & 240 & 192.410 & 35.138 & 192.258 & 28.198 & $\begin{array}{l}t=0.041 \\
(p=0.967)\end{array}$ \\
\hline
\end{tabular}

The second investigation that evaluates competencies of coaches from types of sports point of views show those athletes from team sports rated higher score of their coaches than those from individual sports in all dimensions. Such results indicate that coaches for team sports are more competent in playing their roles for motivating, deciding game strategy, introducing good coaching techniques and successfully building characters among athletes.

Table 4: Student-athletes Perceptions on Coaching Competency in Terms of Types of Sports

\begin{tabular}{|c|c|c|c|c|c|c|c|c|}
\hline \multirow{3}{*}{$\begin{array}{l}\text { Dimension of } \\
\text { Competency }\end{array}$} & \multirow{3}{*}{$\begin{array}{l}\text { Num. } \\
\text { of } \\
\text { items }\end{array}$} & \multirow{3}{*}{$\begin{array}{l}\text { Min. } \\
\text { score }\end{array}$} & \multirow{3}{*}{$\begin{array}{l}\text { Max. } \\
\text { score }\end{array}$} & \multicolumn{4}{|c|}{ Types of sports } & \multirow{3}{*}{$\begin{array}{l}\text { Test } \\
\text { differences } \\
\text { between } \\
\text { groups }\end{array}$} \\
\hline & & & & \multicolumn{2}{|c|}{ Individual } & \multicolumn{2}{|c|}{ Team } & \\
\hline & & & & $M$ & $S D$ & $M$ & $S D$ & \\
\hline Motivation & 7 & 7 & 70 & 57.11 & 8.76 & 54.80 & 12.52 & $\begin{array}{l}t=1.930 \\
(p=0.55)\end{array}$ \\
\hline Games strategy & 7 & 7 & 70 & 56.73 & 9.11 & 53.73 & 10.58 & $\begin{array}{l}t=2.680^{* *} \\
(p=0.008)\end{array}$ \\
\hline Techniques & 6 & 6 & 60 & 48.74 & 7.62 & 46.54 & 9.40 & $\begin{array}{l}t=2.269^{*} \\
(p=0.024)\end{array}$ \\
\hline $\begin{array}{l}\text { Character } \\
\text { building }\end{array}$ & 4 & 4 & 40 & 32.61 & 5.21 & 31.35 & 6.05 & $\begin{array}{l}t=1.977^{*} \\
(p=0.049)\end{array}$ \\
\hline Total coaching & 24 & 24 & 240 & 195.287 & 29.788 & 186.941 & 36.175 & $\begin{array}{l}t=2.198^{*} \\
(p=0.029)\end{array}$ \\
\hline
\end{tabular}

Such findings can be described by the fact that a coach for a team sports needs more skills in managing, guiding and monitoring many athletes in the team. Such additional competency elements can be identified from the significant results of t-statistic which are all dimensions except motivation. Therefore, these additional competency elements include his ability: (i) to identify strengths and weaknesses of every player in a team before a final strategy for combination of players be made to oppose a rival team, (ii) to apply appropriate guidance techniques and game strategy that is effective to lead the team to win a match and (iii) to create responsibility among the players so that they are functioning as a dynamic team during a match. In contrast, a coach for individual sports may provide a hundred percent attention on his athlete. However, this result cannot be simply judged that coaches for team sports 
are more superior to coaches for individual sports.

In comparison of the perceptions between winners and losers, the results revealed that there was no significant difference on each of the dimension of coaching competency. The mean scores of both groups are just indicated a small differences. Thus, this could be implied that regardless of whether they won or lost in the competition, the student-athletes perceived the competencies level of the coaches have demonstrated with equal competencies in coaching. These findings could be explained that the perceptions of student-athletes are more likely being influenced by their previous sporting experiences as an athlete whether before they were with the current team or with the current team for quite some times under the supervision of different coaches, and thus, as a result of that experiences they were not too dependent from their current coaches.

Table 5: Student-athletes Perceptions on Coaching Competency in Terms of Performance in the Competitions (win-loss)

\begin{tabular}{|c|c|c|c|c|c|c|c|c|}
\hline \multirow{3}{*}{$\begin{array}{l}\text { Dimension of } \\
\text { Competency }\end{array}$} & \multirow{3}{*}{$\begin{array}{l}\text { Num. } \\
\text { of } \\
\text { items }\end{array}$} & \multirow{3}{*}{$\begin{array}{l}\text { Min. } \\
\text { score }\end{array}$} & \multirow{3}{*}{$\begin{array}{l}\text { Max. } \\
\text { score }\end{array}$} & \multicolumn{4}{|c|}{ Performance in the competitions } & \multirow{3}{*}{$\begin{array}{l}\text { Test } \\
\text { differences } \\
\text { between } \\
\text { groups }\end{array}$} \\
\hline & & & & \multicolumn{2}{|c|}{ Winner } & \multicolumn{2}{|c|}{ Loser } & \\
\hline & & & & $M$ & $S D$ & $M$ & $S D$ & \\
\hline Motivation & 7 & 7 & 70 & 56.47 & 10.03 & 55.90 & 10.91 & $\begin{array}{l}t=0.481 \\
(p=0.631)\end{array}$ \\
\hline Games strategy & 7 & 7 & 70 & 56.06 & 10.44 & 54.93 & 9.00 & $\begin{array}{l}t=1.022 \\
(p=0.308)\end{array}$ \\
\hline Techniques & 6 & 6 & 60 & 48.25 & 8.92 & 47.44 & 7.78 & $\begin{array}{l}t=0.844 \\
(p=0.400)\end{array}$ \\
\hline $\begin{array}{l}\text { Character } \\
\text { building }\end{array}$ & 4 & 4 & 40 & 32.36 & 5.69 & 31.83 & 5.46 & $\begin{array}{l}t=0.844 \\
(p=0.399)\end{array}$ \\
\hline Total coaching & 24 & 24 & 240 & 193.494 & 33.847 & 190.355 & 31.126 & $\begin{array}{l}t=0.840 \\
(p=0.401)\end{array}$ \\
\hline
\end{tabular}

\subsection{Relationship between Performance and Length of Experience}

In order to address research question (c) asked "Does the performance of athletes is influenced by length of experience under supervision of their coaches? We performed some investigations to determine whether performance of athletes is influenced by length of experience under supervision of their coaches. Figure 1 shows the fluctuations of both groups of athletes who won and loss in the competitions based on their cumulative length of supervision. 


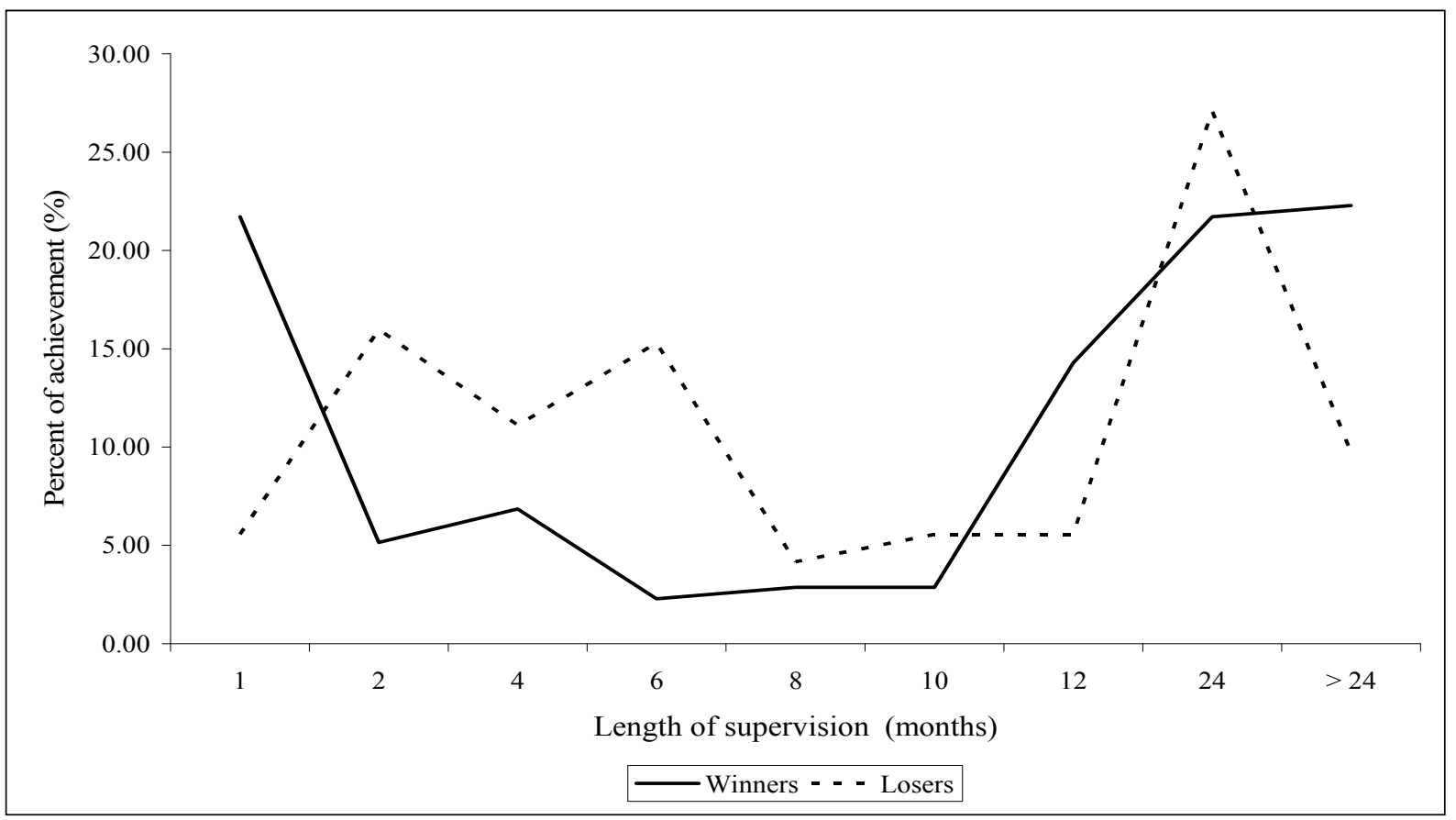

Figure 1: Correlation between Performance and Length of Supervision

Fluctuations as depicted in Figure1 can be summarised in three phases. Phase I is for beginner where the athletes are just a month with the coaches. In Figure 1 we can see that there are more athletes who won in the competitions. Such result may explain a good start communication between coaches and athletes where both parties were at the similar agreements on choosing they types of training, strategy and tactics of games. It was also not possible that the athletes themselves were talented for the games which they possessed the skills and techniques prior to join universities' teams.

Phase II ( 2 to 10 months) however has reversed result where the percentage of athletes who loss in the competitions was larger than the winners. If we consider that students join the universities' teams at the beginning of their registration to the university, then the first six months or the first one year at the university was a period where a student struggles to balance their academic classes and training sessions. In Malaysia, most universities allow the new students to register for 15 to 21 credit hours for courses thus it is more to say that the students will be burdened with many assignments. Consequently, students have to limit themselves to have extra training hours. Besides, achievement in sports especially at the university environment has not been recognised with extra points for grading purposes, therefore one may take for granted that there is no issue whether you are a winner or a loser.

Phase III (after 10 months) depicts another different scenario where more athletes performed well in their games in general. This gives us some information that athletes have aligned themselves with the trainings and coaches. A result of chi-square test indicates $\chi_{8}^{2}=57.601(\mathrm{p}$-value $<0.000)$ which means that the length of time an athlete was supervised may influence his/her performances in the competitions. The behaviour of influence was presented in Figure 1.

\section{Conclusion}

Results from this study have several important implications. This study has successfully demonstrated some levels of competency displayed by the coaches in public universities. Coaches' coaching competencies showed different approaches and styles of coaching to their athletes by using motivation, game's strategy, athletes' character building, and implement effective techniques in sports training. Thus, given this knowledge, the coaches can use the important structures in the coaching competencies as a guide to act or behave as necessary in appropriate circumstances. This is because the behavior of coaches that do not suit the needs of athletes and organizations, if adopted would bring 
adverse implications on the development and progress of the athletes and the team.

In addition, the knowledge gained from this study can provide valuable input to the development of coaching development program to the parties concerned, such as universities, the Ministry of Higher Education, the National Sports Council, and sports bodies. The results of this study can provide meaningful information to plan the structure of the sports coaching education program to be more complete and systematic. The study to some extent can contribute in the selection procedure of an effective coach in preparing an excellent sports team and sound athlete.

The results of this study could also encourage the coaches to appreciate the differences of their athletes. In particular, the coaches can use these findings to improve their understanding of the student-athletes from different backgrounds who observe the level of their coaching competencies compared to coaches who have less knowledge of cultural values and experience. Thus, these findings can be used to illustrate how the collective reality of the coaches' approaches and strategies in terms of providing encouragement, games strategies, technical skills and character building of the athletes.

It is recommended that future studies on the coaches' coaching competency should take into account on other variables such as athletes' past experience, level of competition, the status of athletes and family backgrounds that may have influenced on the perceptions of student-athletes. Besides, this study also suggests that future studies should also utilize qualitative methods as well to acquire more objective data. It is hoped that there are other researchers also interested to conduct studies pertaining to this issues in providing meaningful contribution to the discipline of sports education, especially in management and sports science in Malaysia.

\section{References}

Abdul Hafidz Omar \& Norazman Abd Majid. (November, 2004). The relationship between coaches' profile and athletes' performance. Paper presented at 1st Regional Conference on Human Performance at Hilton Hotel, Petaling Jaya, Malaysia.

Adams, S. (1979). A comprehensive plan for evaluating coaches. Athletic Purchasing and Facilities, 1, 14-15, 19-20.

Brislin, W. R. (1971). Back-translation for cross-cultural research. Journal of Cross-Cultural Psychology, 1(13), 185-216.

Chelladuarai, P., \& Saleh, S. D. (1978). Preferred leadership in sport. Canadian Journal of Applied Sport Sciences, 3, 85-92.

Chelladurai, P. (1990). Leadership in sports: a review. International Journal of Sport Psychology, 21, 328-354.

Chelladurai, P., \& Arnot, M. (1985). Decision styles in coaching: Preferences of basketball players. Research Quarterly for Exercise and Sport, 56, 15-24.

Chelladurai, P., \& Saleh, S. D. (1980). Dimensions of leader behavior in sport: Development of a leadership scale. Journal of Sport Psychology, 2, 34-45.

Cratty, B. J. (1989). Psychology in contemporary sport (3rd. ed). New Jersey: Prentice-Hall.

Dalton, M. (1997). Are competency models a waste? Training and Development, 51(10), 46-50.

Fung, L. (2002). Task familiarity and task efficacy: A study of sports coaches. Perceptual and Motor Skills, 95, 367-372.

Hersey, P., \& Blanchard, K. H. (1977). Management of organization behavior ( $3^{\text {rd }}$ ed). Englewood cliffs, New Jersey: Prentice-Hall, Inc.

Horn, T. S. (1992). Advance in sport psychology $\left(2^{\text {nd }}\right.$ ed). Champaign, IL: Human Kinetics.

Horn, T. S. (2002). Coaching effectiveness in sport domain: Advances in sport psychology. Champaign, IL: Human Kinetics.

House, R. J. (1971). A Path-Goal theory of leader effectiveness. Administrative Science Quarterly, 16, 321-338. http://dx.doi.org/10.2307/2391905

Khairul Anuar Mokhtar. (1990). KOAM amal sistem lapuk. Berita Harian, p. 22.

Khoo, Kay Kim. (1991). Jurulatih Malaysia tiada inisiatif. Berita Harian, p. 21.

Khoo, Kay Kim. (1991). Worden belum faham budaya pemain. Berita Harian, p. 23. 
Khoo, Kay Kim. (1994). Jurulatih Malaysia perlu kreatif tingkat keupayaan. Berita Harian, p. 27.

Khoo, Kay Kim. (1995). Jurulatih cetek ilmu lebih gemar jadi peniru. Berita Harian, p. 23.

Kuga, D. J. (1993). Evaluating high school coaches - perception of coaches and student athletes. Journal of Physical Education, Recreation, and Dance, August, 84-87.

Lim, Khong Chiu. (1995). Coach leadership behaviours and their relationship to athletes'achievement orientation and satisfaction. Unpublished Master Thesis. Universiti Sains Malaysia.

Manning, C. T. (2007). Relationship among team collective efficacy, cohesion, and coaching competency in sports. Unpublished Doctoral Thesis. Utah State University.

Martens, R. (1987). Coaches guide to sport psychology. Champaign, IL: Human Kinetics.

Myers, N. D., Wolfe, E. W., Maier, K. S., Felt, D. L., \& Reckase, M. D. (2006). Athletes' evaluations of their head coach's coaching competency. Research Quarterly for Exercise and Sport, 77(1), 111-121. http://dx.doi.org/10.5641/027013606X13080769704082

Paling, D. (2002). Keeping coaches on track: Evaluating coaches is a key part of your job. But exactly what criteria should you use? And how do you communicate? Athletic Management, 14(2), 53-54; 56-57.

Phillips, M. B. (2007). Student-athletes perceptions of head men's basketball coaching competencies at 15 selected NCCAA division II Christian Colleges. Unpublished Doctoral Thesis, Middle Tennessee State University.

Rahim Harun. (1992). Jurulatih asing-Suatu analisa keberkesanan. Sukan Malaysia, 1, 9-12.

Schliesman, E. S. (1987). Relationship between the congruence of preferred and actual leader behavior and subordinate satisfaction with leadership. Journal of Sport Behavior, 10, 157-166.

Sieh Kok Chi. (September, 2004). Shortcomings of Malaysian sports. The Star, p.12.

Smoll. F. T., Smoll, R.E., \& Hunt, E. B. (1977). A system for the behavior assessment of athletic coaches. Research Quarterly, 48, 401-407.

Terry, P. C. (1984). The coaching preferences of elite athletes competing at universiade '83. Canadian Journal of Applied Sport Sciences, 9, 201-208. 